\title{
New indicator Escherichia coli strain for rapid and accurate detection of supF mutations
}

\author{
Ruriko Fukushima ${ }^{\dagger}$, Tetsuya Suzuki ${ }^{* \dagger}$ (D) and Hiroyuki Kamiya ${ }^{*}$
}

\begin{abstract}
Background: The supF gene of Escherichia coli is useful for forward mutation analysis in bacterial and mammalian cells used in mutagenesis and DNA repair studies. Indicator E. coli strains, such as KS40/pOF105, have been used to analyze supF mutations. However, KS40/pOF105 is not enough to select supF mutants on nutrient-rich agar plates. Therefore, in this study, a new indicator $E$. coli strain for rapid and accurate detection of supF mutations was developed.

Results: The gyrA and rpsL genes with an amber mutation were integrated into the chromosomal DNA of E. coli KS40 to produce a new indicator strain, RF01. RF01 cells transformed by the wild-type supF gene were sensitive to nalidixic acid and streptomycin on LB agar plates. supF mutant frequencies and mutation spectra in RF01 were similar to those in KS40/pOF105. In addition, some mutations in supF were only detected in RF01.
\end{abstract}

Conclusion: RF01 is a new and useful indicator E. coli strain for analyzing supF mutations.

Keywords: supF mutation assay, Indicator Escherichia coli strain, gyrA, rpsL

\section{Background}

The supF gene of Escherichia coli codes for an amber suppressor transfer RNA (tRNA) that translates the amber codon (UAG) into tyrosine [1, 2]. supF mutations stop translation of genes with an amber mutation. On the basis of this property, supF-bearing plasmids have been developed to study chemical mutagenesis and DNA repair mechanisms by using selectable marker genes with an amber mutation in host bacteria [3-6].

E. coli MBM7070 has an amber mutation in lacZ, and supF mutants can be identified by colorimetric screening using 5-bromo-4-chloro-3-indolyl- $\beta$-D-galactopyranoside (X-gal) [6]. However, it is difficult to select white mutant colonies from a large number of wild-type (WT) blue colonies and accurately determine low-level mutant

\footnotetext{
* Correspondence: suzukite@hiroshima-u.ac.jp; hirokam@hiroshima-u.ac.jp ${ }^{+}$Ruriko Fukushima and Tetsuya Suzuki contributed equally to this work. Graduate School of Biomedical and Health Sciences, Hiroshima University, 1-2-3 Kasumi, Minami-ku, Hiroshima 734-8553, Japan
}

frequencies in MBM7070. Akasaka et al. (1992) established E. coli $\mathrm{KS} 40 / \mathrm{pKY} 241$ to overcome this difficulty [7]. KS40 is a nalidixic acid-resistant ( $g y r A)$ MBM7070 derivative, and pKY241 is a plasmid bearing the gyrA gene with an amber mutation. WT $\operatorname{supF}\left(\operatorname{supF}^{+}\right)$-transformed KS40/pKY241 cells are sensitive to nalidixic acid, and supF mutants are selected as white colonies on nalidixic acid- and X-gal-containing agar plates. However, this antibiotic system does not work properly for selecting supF mutants, and false-positive mutant (blue) colonies are found on selection agar plates. To improve this antibiotic system, Obata et al. (1998) developed the indicator strain E. coli KS40/pOF105 for positive screening of supF mutants in order to measure low-level mutant frequencies [4], and KS40/pOF105 has been used to analyze mutations generated in bacterial and mammalian cells [8-20]. KS40 is also deficient in rpsL in addition to gyrA, and the pOF105 plasmid contains structural gyr$A^{a m}$ and $r p s L^{a m}$, which have an amber mutation in one 
of their tyrosine codons. Therefore, the supF $F^{+}$plasmid transforms KS40/pOF105 to nalidixic acid- and streptomycin-sensitive and $\beta$-galactosidase-positive cells. In contrast, KS40/pOF105 cells remain resistant to nalidixic acid and streptomycin and $\beta$-galactosidase-negative when mutant supF (supF) plasmids are introduced. Therefore, transformants with supF plasmids form white or faint-blue colonies on nalidixic acid-, streptomycin-, and X-gal-containing selection agar plates. supF mutants can be successfully selected by dual antibiotic system on minimal agar plates [4]. However, some blue false mutant colonies, which are transformed by $\operatorname{supF}^{+}$plasmids, often appear when selection agar plates contain a nutrient-rich medium and X-gal [15].

We hypothesized that rpsL ${ }^{\text {am }}$ expression from pOF105 is suppressed in nutrient-rich media containing tryptophan since the expression of rpsL ${ }^{a m}$ is regulated under the tryptophan promoter. When minimal medium is used, as previously described [4], both nalidixic acid and streptomycin effectively select supF mutants. In contrast, in a nutrient-rich medium, only nalidixic acid selection might be effective, and spontaneous mutations in genes involved in nalidixic acid dynamics in E. coli or gyrA $A^{a m}$ in pOF105 might allow sup $F^{+}$colony formation. The culture time until colony formation on minimal agar plates is commonly longer compared to nutrient-rich agar plates. In addition, the preparation of minimal agar plates is more complex than that of LB agar plates consisted of nutrient-rich because many components must be added after autoclaving.

In this study, a new indicator E. coli strain allowing double selection by nalidixic acid and streptomycin on nutrient-rich agar plates and the rapid and accurate detection of supF mutations was established.

\section{Materials and methods Materials}

Oligodeoxynucleotides were purchased from Integrated DNA Technologies (Coralville, IA, USA), Hokkaido System Sciences (Sapporo, Japan), and Sigma Genosys Japan (Ishikari, Japan) (Table 1). U2OS cells were obtained from ATCC (ATCC HTB-96). KS40 and KS40/pOF105 were kindly provided by Professor Tatsuo Nunoshiba of International Christian University [4].

\section{Construction of a temperature-sensitive $\lambda$-red operon- expressing plasmid}

To produce temperature-sensitive pMW119ts, the alanine 56 substitution to valine $(167 \mathrm{C} \rightarrow \mathrm{T})$ in repA was introduced into pMW119 (Nippon Gene, Tokyo, Japan)

Table 1 Oligodeoxynucleotide sequences used in this study

\begin{tabular}{|c|c|}
\hline Name & Sequence $\left(5^{\prime}\right.$ to $\left.3^{\prime}\right)$ \\
\hline repA(A56V) S & ATAACCAATACGTTCAGATGATGAA \\
\hline repA(A56V) AS & TTCATCATCTGAACGTATTGGTTAT \\
\hline pBAD-CYC(X) Fw & TCAGATAAAATATTTTGCATAATGTGCCTGTCAAA \\
\hline pBAD-(MCS) Rv & TGCAGAAGCTTCCTCCTGTTAGC CCAAAAAAACGGGTATGGAG \\
\hline rrnB term-(pBAD) Fw & GAGGAAGCTTCTGCAGCTCGAG TGCCTGGCGGCAGTAGCGCG \\
\hline rrnB term-CYC(D) Rv & GCAAATTCGACCCGG AAGGCCCAGTCTITCGACTG \\
\hline Red (pBADMCS-H) Fw & GGGCTAACAGGAGGA TTATAAAAAATGGATATTAA \\
\hline Red (pBADMCS-H) Rv & CACTCGAGCTGCAGA ATTCTTCGTCTGTTTCTACT \\
\hline rpsL pro Sall Fw1 & CCAGTCGACTGGCCTGGTGATGGCGGGAT \\
\hline rpsL Lower3 & CACGAGTACATACGCCACGT \\
\hline gyrA SgrAl Fw & TATTCTGCTGACGCACGGCATTCATTGGCACTTCT \\
\hline gyrA SgrAl Rv & AGAAAAAAGGCTGCACCTTGTGTATAGCCAGCCAT \\
\hline pCpGfree MAR(-) VF & TGTGGTATGGAATTC TTAAAATCAGCAGTTCAACCTGTT \\
\hline pCpGfree MAR(-) VR & CTCCTGCAGGAATTC TTAAAACAGTAGTTGACAATTAAACAT \\
\hline $\operatorname{arsB}(500) \mathrm{Fw}$ & GGCAGCCGAAAGGTTAGGC \\
\hline $\operatorname{arsB}(500) \operatorname{Rv}$ & CCATCAATGGACAACGCGCC \\
\hline HL-CYC FW & AAACAAAAAAAACCCCGCTTCGGCGGGGTTITITTGCACCTGAAGTCAGCCCCAT \\
\hline HL-CYC RV & AAACAGCGAAAAAACCCCGCCCTGTCAGGGGCGGGGTTITTGCGCGAGCGTAGCGAGTCAGTGA \\
\hline supF RM Fw & CGCCGTCTCGGTTATTGTCTCATGAGCGG \\
\hline supF RM Rv & GCCCGTCTCAGCTCTTGATCCGGCAAACA \\
\hline supFcomp RM Fw & GCCCGTCTCAGAGCTACCAACTCTTTTTC \\
\hline supFcomp RM Rv & CGCCGTCTCATAACCCTGATAAATGCTTC \\
\hline
\end{tabular}


using the QuikChange Site-Directed Mutagenesis Kit (Agilent Technologies, Santa Clara, CA, USA) and primers repA(A56V) $\mathrm{S}$ and $\operatorname{repA}(\mathrm{A} 56 \mathrm{~V})$ AS. The ara$B A D$ promoter and the $r r n B$ terminator were amplified by PCR using E. coli BL21(DE3) genomic DNA as a template and two primer sets: $\mathrm{pBAD}-\mathrm{CYC}(\mathrm{X}) \mathrm{Fw}$ and pBAD-(MCS) Rv and rrnB term-(pBAD) Fw and rrnB term-CYC(D) Rv. Next, to construct pBAD-MCS, the PCR fragments were combined with a short fragment of pACYC184 (Nippon Gene) digested with $\mathrm{Xba}$ I and Drd I using the GeneArt Seamless Cloning and Assembly Enzyme Mix (Thermo Fisher Scientific, Waltham, MA, USA). The $\lambda$-red operon was amplified by PCR using $\lambda$ DNA (New England Biolabs, Ipswich, MA, USA) as a template and the primer set Red (pBADMCS-H) Fw and
Red (pBADMCS-H) Rv, and the PCR fragments were then joined with Hind III-digested pBAD-MCS. Next, the $\lambda$-red operon expression cassette from the $\operatorname{araBAD}$ promoter to the $\operatorname{rrnB}$ terminator was amplified and ligated into the Sma I site of pMW119ts in the reverse direction of lacZ $\alpha$. Finally, the E. coli KS40 strain transformed by the resultant plasmid was cultured at $30^{\circ} \mathrm{C}$ in a medium containing $0.2 \%$ arabinose, and competent cells were prepared for electroporation.

\section{Establishment of the $E$. coli RF01 strain}

Structural $g y r A^{a m}$ and $r p s L^{a m}$ were integrated into E. coli chromosomal DNA using the $\lambda$-red recombination system, as previously described with slight modifications [21, 22].

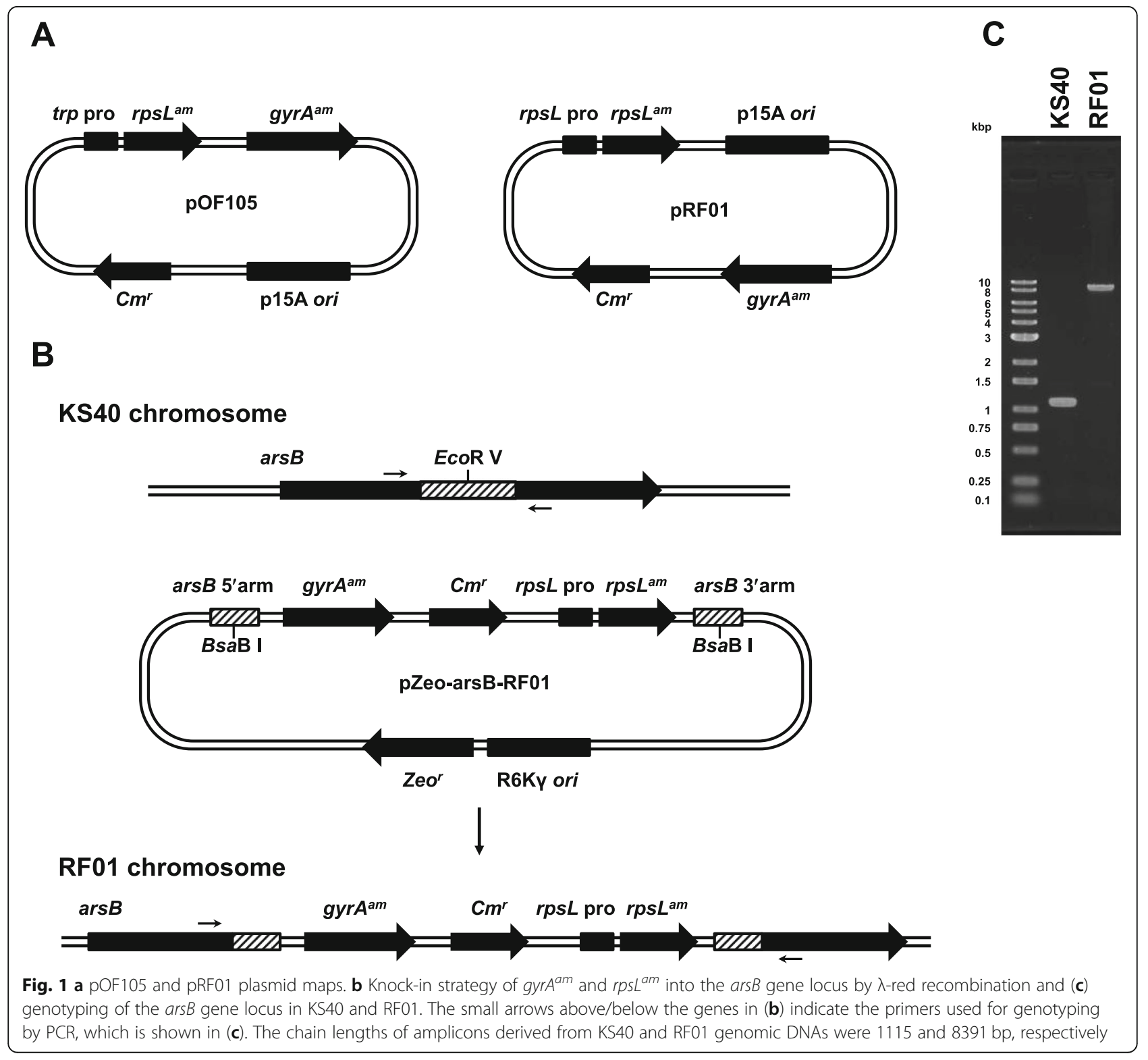


The rpsL promoter was amplified using pSSW [23] as a template and the primer set rpsL pro Sall Fw1 and rpsL Lower3. The amplified fragment was digested with restriction enzymes Sph I and Sal I and ligated with the large pOF105 fragment also digested with Sph I and Sal I, and the plasmid was digested with BamH I and Bgl II, followed by self-ligation to remove $g y r A^{a m}$. Subsequently, the gene amplified using pOF105 as a template and the primer set gyrA SgrAI Fw and gyrA SgrAI Rv was reintroduced into the SgrA I site using the GeneArt Seamless Cloning and Assembly Enzyme Mix to produce pRF01 (Fig. 1a).

The DNA region containing the Zeocin-resistance gene plus $\mathrm{R} 6 \mathrm{~K} \gamma$ ori was amplified by PCR using pCpGfree-mbSeap [24] as a template and the primer set pCpGfree MAR(-) VF and pCpGfree MAR(-) VR. It was then joined with the PCR-amplified arsB fragment using BL21(DE3) genomic DNA as a template and the primer set arsB (500) Fw and arsB (500) Rv in the same direction as the Zeocin-resistance gene. To construct pZeo-arsB-RF01 (Fig. 1b), the resultant plasmid was digested with $E c o$ R V and ligated with PCR fragments amplified using pRF01 as a template and the primer set HL-CYC Fw and HL-CYC Rv. Next, 100 ng of BsaB Idigested pZeo-arsB-RF01 was electroporated into $\lambda$-redexpressing KS40 competent cells and selected on LB agar plates containing $5 \mu \mathrm{g} / \mathrm{mL}$ chloramphenicol at $37^{\circ} \mathrm{C}$. Finally, the genotype and ampicillin sensitivity of chloramphenicol-resistant $E$. coli was confirmed, and the E. coli strain was named RF01 (Fig. 1b and c).

\section{Introduction of random mutations into supF}

supF was amplified by random mutagenesis PCR using pZ189-T_E107K/D402E [17] as a template and the

A

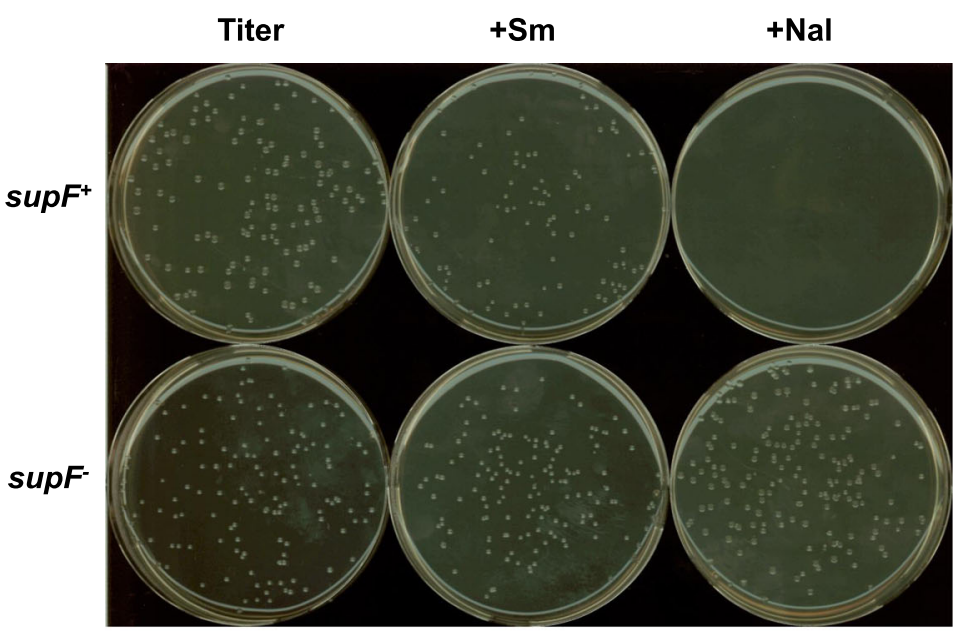

B

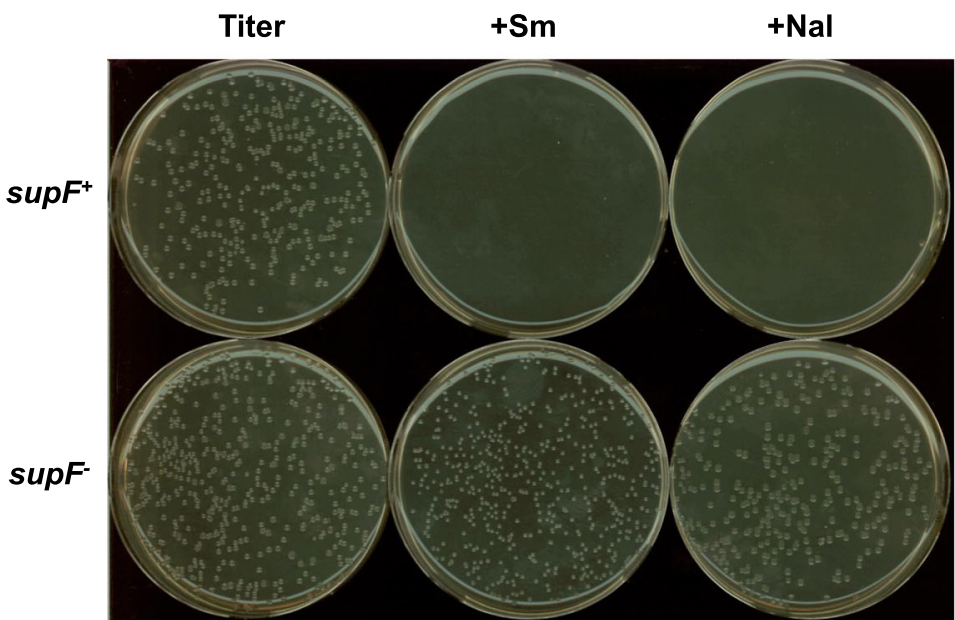

Fig. 2 Nalidixic acid and streptomycin sensitivity of (a) KS40/pOF105 and (b) RF01 cells transformed with the plasmids supF ${ }^{+}$(pZ189-T_E107K D402E) and supF (pZ189-T_E107K/D402E (122T)). Sm, streptomycin; Nal, nalidixic acid 
primer set supF RM Fw and supF RM Rv, as previously described [25]. Briefly, a $50 \mu \mathrm{L}$-reaction mixture containing $1 \times$ Taq buffer (Toyobo, Osaka, Japan), $0.2 \mathrm{mM}$ dATP, $0.2 \mathrm{mM}$ dGTP, $1 \mathrm{mM}$ dCTP, $1 \mathrm{mM}$ dTTP, 0.5 $\mathrm{mM} \mathrm{MnCl}_{2}, 0.3 \mu \mathrm{M}$ each primer, $50 \mathrm{ng}$ of pZ189-T_ E107K/D402E, and 2.5 units of Taq DNA polymerase (Toyobo) was amplified by PCR for 35 cycles of $94{ }^{\circ} \mathrm{C}$ for $30 \mathrm{~s}, 55^{\circ} \mathrm{C}$ for $30 \mathrm{~s}$, and $72{ }^{\circ} \mathrm{C}$ for $45 \mathrm{~s}$. The pZ189- $\mathrm{T}_{-}$ E107K/D402E backbone was amplified using the primer set supFcomp RM Fw and supFcomp RM Rv under the standard PCR condition using the KOD One PCR Master Mix (Toyobo). Both DNA fragments were digested with Esp3 I and combined, and the ligation product was introduced into E. coli DH10B. Finally, $\sim 10^{5}$ colonies on ampicillin-containing agar plates were harvested, followed by plasmid extraction, and the plasmid was named pZ189-RM.

\section{Comparison of recovery from electroporation of $E$. coli RF01 vs. KS40/pOF105}

A mixture of equal amounts of pZ189-T_E107K/D402E and pZ189-T_E107K/D402E (122 T) [17] was electroporated into RF01 and KS40/pOF105 cells. Immediately after the addition of SOC medium and after a 1-h recovery, the cultures were seeded on LB agar plates containing $150 \mu \mathrm{g} / \mathrm{mL}$ ampicillin, $30 \mu \mathrm{g} / \mathrm{mL}$ chloramphenicol, and $80 \mu \mathrm{g} / \mathrm{mL}$ X-gal.

\section{supF mutation analyses}

pZ189-T_E107K/D402E was transfected into human U2OS cells using Lipofectamine 2000 according to the manufacturer's instructions, and the plasmids were extracted as previously described [26]. The extracted plasmids or mixtures of pZ189-T_E107K/D402E and pZ189RM were introduced into RF01 and KS40/pOF105 cells, and supF mutant frequencies were calculated. Finally, mutation spectra of the plasmid from E. coli strains transformed by pZ189-RM were analyzed.

The colony sizes are visually judged based on the sizes of colonies on titer plates.

\section{Statistical analysis}

Statistically significant differences in blue-to-white colony ratios and supF mutant frequencies between RF01 and KS40/pOF105 were examined by Student's $t$-test. The level of statistical significance was set at $P<0.05$.

\section{Results}

Establishment of a new indicator strain for supF mutation analyses

We transformed KS40/pOF105 cells with a supF $F^{+}$-bearing plasmid and spread them onto LB agar plates containing streptomycin to test our hypothesis that antibiotic sensitivity is ineffective when nutrient-rich agar plates are used. The numbers of colonies on agar plates with and without streptomycin were similar, although the colony size was smaller on selection agar plates than on titer plates (Fig. 2a). This result indicated that selection with the antibiotic is ineffective when KS40/pOF105 and streptomycin-LB agar plates are used.

To enable selection by streptomycin in nutrient-rich media, such as LB medium, the tryptophan promoter in pOF105 was replaced with the rpsL promoter for constitutive $r p s L^{a m}$ expression in tryptophan-containing media. The constructed plasmid, pRF01 (Fig. 1a), was introduced into KS40. KS40/pRF01 cells transformed with a supF $F^{+}$ bearing plasmid showed sensitivity to both nalidixic acid and streptomycin (data not shown). However, the colony size of supF $F^{+}$plasmid-bearing KS40/pRF01 cells was smaller than that of $\sup F^{+}$plasmid-bearing KS40/pOF105 cells and supF plasmid-bearing KS40/pRF01 cells on LB titer plates (data not shown). This result indicated that high-level rpsL expression from multiple plasmid copies negatively affects growth.

A new supF mutation indicator strain, RF01, was then established by integrating $g y r A^{a m}$ and $r p s L^{a m}$ into the $\operatorname{ars} B$ gene locus in the KS40 chromosomal DNA to reduce the copy number (Fig. 1b). The genotypes were confirmed by PCR (Fig. 1c, expected lengths of PCR products; KS40, $1115 \mathrm{bp}$; RF01, $8391 \mathrm{bp})$. RF01 cells transformed with a sup $F^{+}$-bearing plasmid showed sensitivity to nalidixic acid and streptomycin (Fig. 2b). In addition, the colony size of sup $F^{+}$-transformed RF01 cells on titer plates was not different from those of supF $F^{+}$-transformed KS40/pOF105 and supF mutant $(122 \mathrm{G} \rightarrow \mathrm{T})$-transformed RF01 cells. The blue-to-white colony ratios were nearly identical for RF01 and KS40/pOF105 at 0 and $1 \mathrm{~h}$ postelectroporation for an $\sim$ 1:1 mixture of WT and mutant plasmids (Fig. 3),

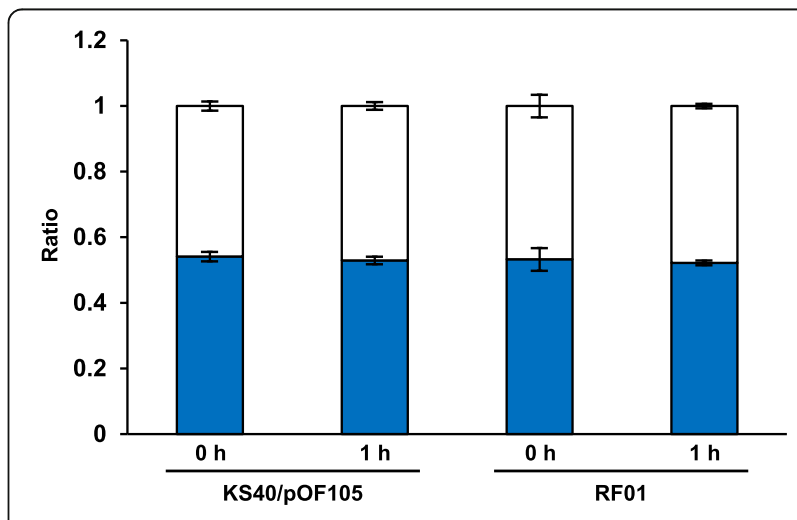

Fig. 3 Comparison of blue-to-white colony ratios for KS40/pOF105 and RF01 cells. Equal amounts of supF $F^{+}$(pZ189-T_E107K/D402E) and supF (pZ189-T_E107K/D402E (122 T)) plasmids were electroporated into KS40/ pOF105 and RF01, and treated bacteria were placed on LB agar plates containing X-gal 0 and $1 \mathrm{~h}$ postincubation in SOC medium. Blue and white bars indicate blue and white colony ratios. Data are represented as the means \pm SD (standard deviation) of three independent experiments. There were no significant differences between 0 and $1 \mathrm{~h}$ postelectroporation and between RF01 and KS40/pOF105 
A

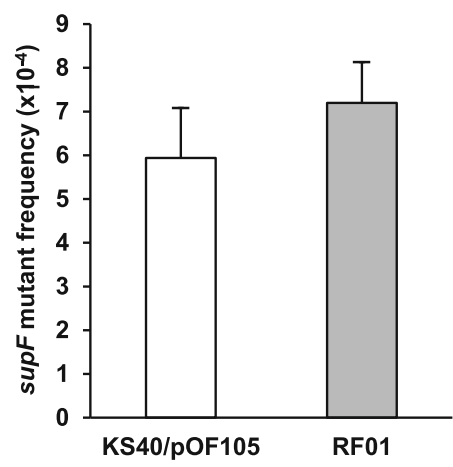

B

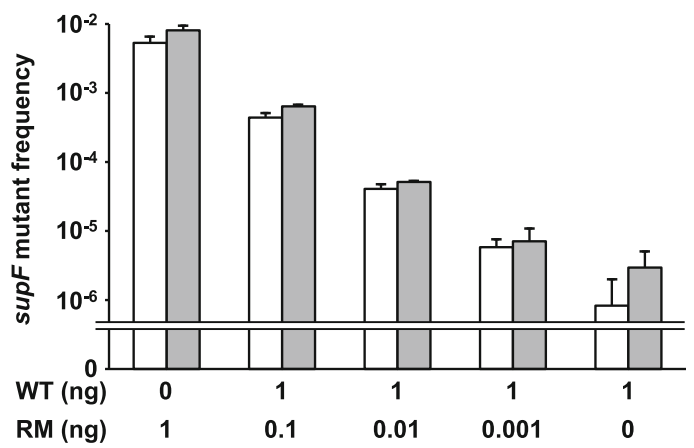

Fig. 4 (a) supF mutant frequencies of plasmid replicated in U2OS cells and (b) mixtures of randomly mutagenized supF (pZ189-RM) and supF ${ }^{+}$ (pZ189-T_E107K/D402E) plasmids in KS40/pOF105 and RF01. pZ189-RM was mixed with pZ189-T_E107K/D402E at the ratios shown in (b). White and gray bars indicate KS40/pOF105 and RF01, respectively. Data are represented as the means + SD (standard deviation) of three independent experiments. There were no significant differences between RF01 and KS40/pOF105 in all the supF mutant frequencies

indicating that the postelectroporation recovery rates were similar in RF01 and KS40/pOF105 regardless of the supF genotype and that neither strain had a potential bias in transformant growth during recovery culture.

\section{supF mutation detection capability of RF01 and KS40/ pOF105}

We then compared the $\sup F$ mutation detection capability of RF01 and KS40/pOF105. The pZ189-T_E107K/ D402E plasmid was transfected into human U2OS cells, and the replicated plasmid was recovered from the cells. The supF mutant frequencies (background mutant frequencies) were similar in both RF01 and KS40/pOF105 when the extracted plasmid was introduced into the two strains (Fig. 4a). In addition, we observed no blue (false mutant) colonies of RF01 expressing WT supF on selection agar plates.

In addition, we introduced pZ189-RM bearing randomly mutated $\operatorname{supF} . \mathrm{Mn}^{2+}$ and imbalanced nucleotide conditions were used to induce random mutations in

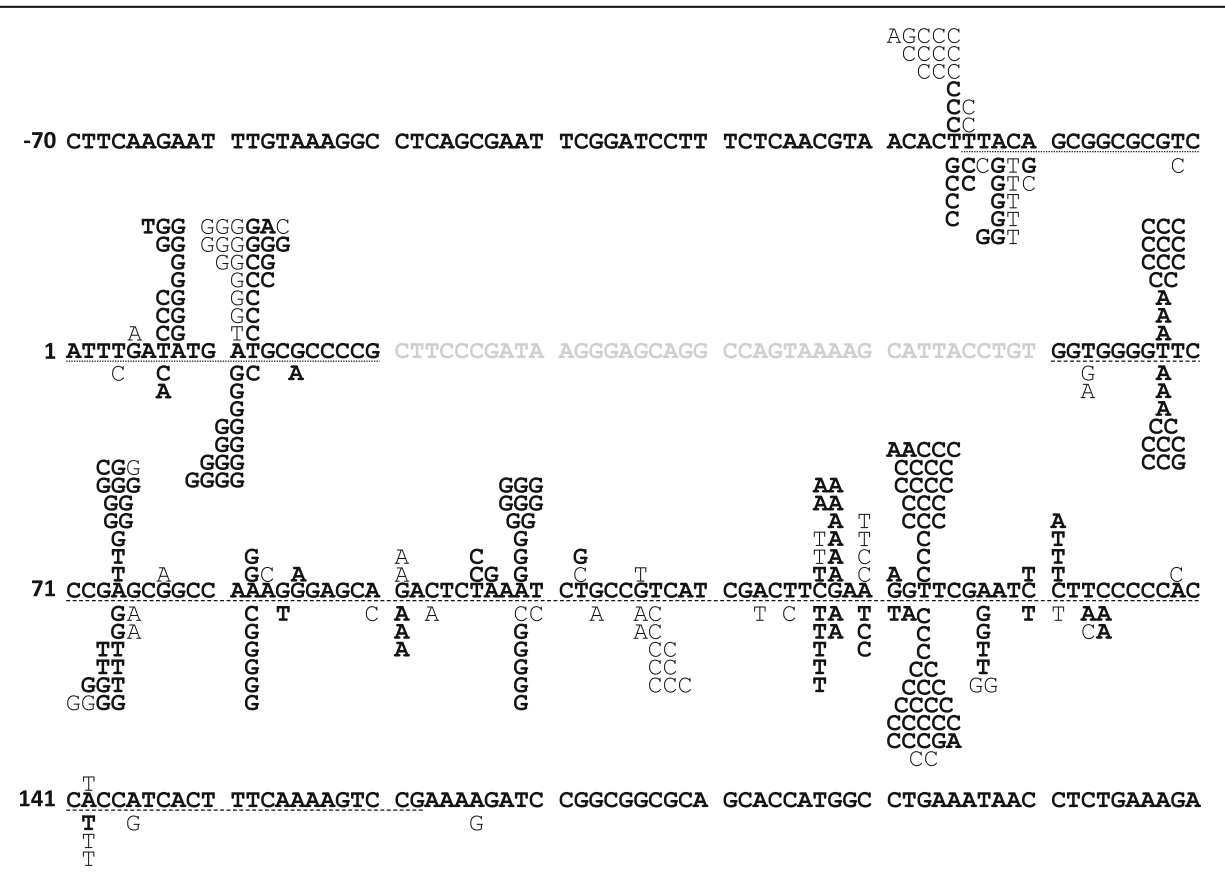

Fig. 5 supF mutation spectra of pZ189-RM introduced into KS40/pOF105 and RF01. The upper strand sequence of supF is shown, and single base substitutions observed in supF mutants of KS40/pOF105 and RF01 are shown above and below the sequence, respectively. Dotted and dashed underlines represent promoter and supF tRNA coding sequences, respectively; gray font indicates the pre-tRNA sequence; thin letters indicate mutants that formed smaller colonies; and bold letters indicate mutants that formed normal-sized colonies 
supF. pZ189-RM and WT pZ189-T_E107K/D402E were mixed in different proportions, and mutant frequencies and mutation spectra in RF01 and KS40/pOF105 were compared. The mutant frequencies of pZ189-RM plus pZ189-T_E107K/D402E were similar in RF01 and KS40/ pOF105, depending on the pZ189-RM-pZ189-T_ E107K/D402E ratio (Fig. 4b). We also analyzed supF mutation spectra in pZ189-RM-transformed mutants (Fig. 5). The mutation spectra were similar for RF01 and KS40/pOF105 cells. However, some mutations were observed in either RF01 or KS40/pOF105, and the colony sizes of some supF mutants seemed different between the two strains. Eight plasmids bearing this type of mutation $(-12 \mathrm{C} \rightarrow \mathrm{T}, 8 \mathrm{~A} \rightarrow \mathrm{G}, 11 \mathrm{~A} \rightarrow \mathrm{G}, 63 \mathrm{~T} \rightarrow \mathrm{A}, 75$

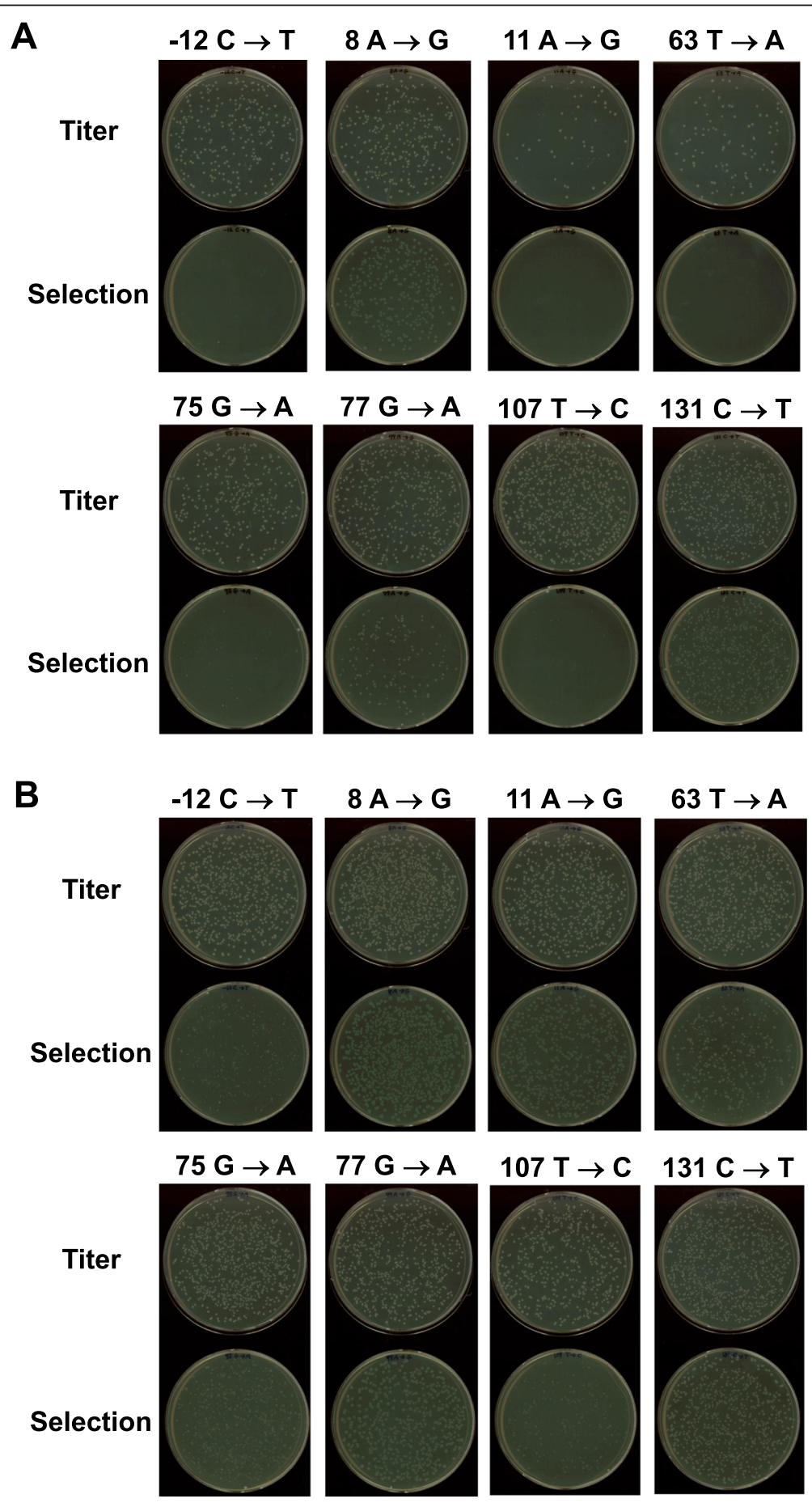

Fig. 6 Colony formation potential of (a) KS40/pOF105 and (b) RF01 transformants with mutant supF plasmids on selection agar plates 
$\mathrm{G} \rightarrow \mathrm{A}, 77 \mathrm{G} \rightarrow \mathrm{A}, 107 \mathrm{~T} \rightarrow \mathrm{C}$, and $131 \mathrm{C} \rightarrow \mathrm{T}$ ) were introduced into RF01 and KS40/pOF105 cells. Plasmids containing mutations detected only in RF01 cells were introduced into KS40/pOF105 cells, and no or tiny colonies appeared on selection agar plates $(-12 \mathrm{C} \rightarrow \mathrm{T}, 63$ $\mathrm{T} \rightarrow \mathrm{A}, 75 \mathrm{G} \rightarrow \mathrm{A}$, and $107 \mathrm{~T} \rightarrow \mathrm{C}$; Fig. 6a). In contrast, all supF mutants in RF01 formed colonies on selection agar plates (Fig. 6b), indicating that RF01 detects more types of supF mutations than KS40/pOF105.

\section{Discussion}

This study established a new $\operatorname{supF}$ mutation indicator $E$. coli strain for rapid and accurate detection on nutrientrich agar plates. supF mutant frequencies and mutation spectra were slightly different between KS40/pOF105 and RF01 (Figs. 4 and 5). In addition, the growth rates of RF01 postelectroporation of $\operatorname{supF^{+}}$ and $\operatorname{supF}$ plasmids were not significantly different (Fig. 3). These findings show that RF01 can be used for supF mutation analyses, similar to KS40/pOF105. Importantly, RF01, unlike KS40/pOF105, does not require minimal agar plates for mutant selection. The culture time to form colonies on minimal agar plates was $2 \mathrm{~d}$, whereas that on LB agar plates was overnight $(16 \sim 18 \mathrm{~h})$ (data not shown). Nalidixic acid and streptomycin in LB agar plates completely inhibited the growth of RF01 cells carrying $\sup F^{+}$, while a significant number of KS40/pOF105 cells containing WT supF appeared as blue colonies on LB agar plates containing nalidixic acid, streptomycin, and X-gal. KS40/ pOF105 requires $\mathrm{X}$-gal, an expensive reagent, for distinguishing between true and false mutant colonies, but RF01 does not. These findings show that the supF mutation assay is more rapid, accurate, and cost effective with RF01 cells. In addition, there are a few supF mutations detected only in RF01, and supF mutation frequencies in RF01 are slightly higher than those in KS40/pOF105. The gyrA ${ }^{a m}$ copy number in RF01 is 1 , so gyrA ${ }^{a m}$ expression in RF01 should be lower than that in KS40/ pOF105. Therefore, partially inactive supF mutations that are difficult to detect in KS40/pOF105 might be detected in RF01. Most of the mutations from the small colonies were found in the promoter of the supF gene, and the regions corresponding to the loops (except for the anticodon trinucleotide) and the central portions of stems of the cloverleaf structure of the supF tRNA. The mutations in the promoter possibly allow slight transcription and those in the loops and the central portions of stems would not completely disrupt the supF tRNA structure. Therefore, these mutations may lead to partial loss of supF function and consequently weak expression of the gyrA and rpsL genes with an amber mutation resulting in forming small colonies on selection agar plates.

\section{Conclusion}

We developed a new indicator E. coli strain, RF01, for the rapid and accurate detection of $\operatorname{supF}$ mutations. RF01 is a novel and useful indicator for supF mutations.

\section{Acknowledgments \\ Not applicable.}

\section{Authors' contributions}

TS and HK contributed to the development of the research proposal and the drafting of the manuscript. TS and RF were involved in the data collection and data analyses. All authors contributed to the writing of the final manuscript.

\section{Funding}

This work was supported in part by the Japan Society for the Promotion of Science (JSPS) KAKENHI grant numbers JP 19 H04278 (HK), JP 17 K12824 (TS), and JP $20 \mathrm{~K} 12181$ (TS)

\section{Availability of data and materials}

The datasets generated and/or analyzed during the current study are available from the corresponding authors on reasonable request.

Ethics approval and consent to participate

Not applicable.

Consent for publication

Not applicable.

\section{Competing interests}

The authors report no conflicts of interest.

Received: 22 July 2020 Accepted: 13 September 2020 Published online: 22 September 2020

\section{References}

1. Smith JD. Gentics of transfer RNA. Annu Rev Genet. 1972;6:235-56.

2. Smith JD. Transcription and processing of transfer RNA precursors. Prog Nucleic Acid Res Mol Biol. 1976;16:25-73.

3. Matsuda T, Yagi T, Kawanishi M, Matsui S, Takebe H. Molecular analysis of mutations induced by 2-chloroacetaldehyde, the ultimate carcinogenic form of vinyl chloride, in human cells using shuttle vectors. Carcinogenesis. 1995;16(10):2389-94

4. Obata F, Nunoshiba T, Hashimoto-Gotoh T, Yamamoto K. An improved system for selection of forward mutations in an Escherichia coli supF gene carried by plasmids. J Radiat Res. 1998;39:263-70.

5. Parris $\mathrm{CN}$, Seidman MM. A signature element distinguishes sibling and independent mutations in a shuttle vector plasmid. Gene. 1992;117:1-5.

6. Seidman MM, Dixon K, Razzaque A, Zagursky RJ, Berman ML. A shuttle vector plasmid for studying carcinogen-induced point mutations in mammalian cells. Gene. 1985;38:233-7.

7. Akasaka S, Takimoto K, Yamamoto K. G:C $\rightarrow$ T:A and G:C $\rightarrow$ C:G transversions are the predominant spontaneous mutations in the Escherichia coli supF gene: an improved lacZ (am) E. coli host designed for assaying pZ189 supF mutational specificity. Mol Gen Genet. 1992;235:173-8.

8. Kamiya H, Makino T, Suzuki T, Kobayashi M, Matsuoka I. Mutations induced by 8-oxo-7,8-dihydroguanine in WRN- and DNA polymerase $\lambda$-double knockdown cells. Mutagenesis. 2018;33:301-10.

9. Kamiya H, Yamaguchi A, Suzuki T, Harashima H. Roles of specialized DNA polymerases in mutagenesis by 8-hydroxyguanine in human cells. Mutat Res. 2010;686:90-5.

10. Kamiya H, Yamazaki D, Nakamura E, Makino T, Kobayashi M, Matsuoka I, et al. Action-at-a-distance mutagenesis induced by oxidized guanine in Werner syndrome protein-reduced human cells. Chem Res Toxicol. 2015;28: $621-8$.

11. Najrana T, Saito Y, Uraki F, Kubo K, Yamamoto K. Spontaneous and osmium tetroxide-induced mutagenesis in an Escherichia coli strain deficient in both endonuclease III and endonuclease VIII. Mutagenesis. 2000;15:121-5. 
12. Nunoshiba T, Obata F, Boss AC, Oikawa S, Mori T, Kawanishi S, et al. Role of iron and superoxide for generation of hydroxyl radical, oxidative DNA lesions, and mutagenesis in Escherichia coli. J Biol Chem. 1999;274:34832-7.

13. Nunoshiba T, Watanabe T, Nakabeppu Y, Yamamoto K. Mutagenic target for hydroxyl radicals generated in Escherichia coli mutant deficient in $\mathrm{Mn}$ - and Fe- superoxide dismutases and Fur, a repressor for iron-uptake systems. DNA Repair (Amst). 2002;1:411-8.

14. Sassa A, Suzuki T, Kanemaru Y, Niimi N, Fujimoto H, Katafuchi A, et al. In vivo evidence that phenylalanine 171 acts as a molecular brake for translesion DNA synthesis across benzo [a] pyrene DNA adducts by human DNA polymerase k. DNA Repair (Amst). 2014;15:21-8.

15. Satou K, Hori M, Kawai K, Kasai H, Harashima H, Kamiya H. Involvement of specialized DNA polymerases in mutagenesis by 8-hydroxy-dGTP in human cells. DNA Repair (Amst). 2009;8:637-42.

16. Suzuki T, Harashima $H$, Kamiya $H$. Effects of base excision repair proteins on mutagenesis by 8-oxo-7,8-dihydroguanine (8-hydroxyguanine) paired with cytosine and adenine. DNA Repair (Amst). 2010;9:542-50.

17. Suzuki T, Harashima H, Kamiya H. Unexpectedly weak impacts of decreased p53 and retinoblastoma protein levels on mutagenesis by 8-Oxo-7,8dihydroguanine (8-Hydroxyguanine). Genes Environ. 2011;33:103-8.

18. Suzuki T, Katayama Y, Komatsu Y, Kamiya H. Analysis of large deletion mutations induced by abasic site analog in human cells. Genes Environ. 2018;40:24.

19. Suzuki T, Katayama Y, Komatsu Y, Kamiya H. Large deletions and untargeted substitutions induced by abasic site analog on leading versus lagging strand templates in human cells. Mutagenesis. 2019;34:421-9.

20. Suzuki T, Kuramoto Y, Kamiya H. Reduction of Werner syndrome protein enhances $\mathrm{G}: \mathrm{C} \rightarrow \mathrm{A}: \mathrm{T}$ transition by $\mathrm{O}^{6}$-methylguanine in human cells. Chem Res Toxicol. 2018;31:319-24.

21. Datsenko KA, Wanner BL. One-step inactivation of chromosomal genes in Escherichia coli K-12 using PCR products. Proc Natl Acad Sci U S A. 2000;97: 6640-5.

22. Sabri S, Steen JA, Bongers $M$, Nielsen LK, Vickers CE. Knock-in/Knock-out (KIKO) vectors for rapid integration of large DNA sequences, including whole metabolic pathways, onto the Escherichia coli chromosome at wellcharacterised loci. Microb Cell Factories. 2013;12:60.

23. Egashira A, Yamauchi K, Yoshiyama K, Kawate H, Katsuki M, Sekiguchi M, et al. Mutational specificity of mice defective in the MTH1 and/or the MSH2 genes. DNA Repair (Amst). 2002:1:881-93.

24. Kanda GN, Miyamoto S, Kobayashi M, Matsuoka I, Harashima H, Kamiya H. Anatomy of plasmid DNAs with anti-silencing elements. Int J Pharm. 2014; 464:27-33.

25. Cadwell RC, Joyce GF. Randomization of genes by PCR mutagenesis. PCR Methods Appl. 1992;2:28-33.

26. Stary A, Sarasin A. Simian virus 40 (SV40) large T antigen-dependent amplification of an Epstein-Barr virus-SV40 hybrid shuttle vector integrated into the human HeLa cell genome. J Gen Virol. 1992;73:1679-85.

\section{Publisher's Note}

Springer Nature remains neutral with regard to jurisdictional claims in published maps and institutional affiliations.

Ready to submit your research? Choose BMC and benefit from:

- fast, convenient online submission

- thorough peer review by experienced researchers in your field

- rapid publication on acceptance

- support for research data, including large and complex data types

- gold Open Access which fosters wider collaboration and increased citations

- maximum visibility for your research: over $100 \mathrm{M}$ website views per year

At BMC, research is always in progress.

Learn more biomedcentral.com/submissions 